\title{
Protective Role of Picralima nitida Seed Extract in High-Fat High- Fructose-Fed Rats
}

\author{
Opeyemi Christianah De Campos $\mathbb{D}^{1,2}{ }^{1,2}$ Daniel Ikpomwosa Osaigbovo, ${ }^{1}$ \\ Titilayo Ifeoluwa Bisi-Adeniyi, ${ }^{1}$ Franklyn Nonso Iheagwam, ${ }^{1,2}$ Solomon Oladapo Rotimi, ${ }^{1,2}$ \\ and Shalom Nwodo Chinedu ${ }^{1,2}$ \\ ${ }^{1}$ Department of Biochemistry, College of Science and Technology, Covenant University, Canaan Land, PMB 1023, Ota, \\ Ogun State, Nigeria \\ ${ }^{2}$ Covenant University Public Health and Wellbeing Research Cluster (CUPHERC), Covenant University, Canaan Land, \\ PMB 1023, Ota, Ogun State, Nigeria
}

Correspondence should be addressed to Opeyemi Christianah De Campos; opeyemi.decampos@covenantuniversity.edu.ng

Received 27 January 2020; Revised 22 September 2020; Accepted 3 October 2020; Published 24 October 2020

Academic Editor: Ergin Murat Altuner

Copyright (C) 2020 Opeyemi Christianah De Campos et al. This is an open access article distributed under the Creative Commons Attribution License, which permits unrestricted use, distribution, and reproduction in any medium, provided the original work is properly cited.

\begin{abstract}
Picralima nitida is a therapeutic herb used in ethnomedicine for the management of several disease conditions including diabetes. This study examined the potential palliative effect of aqueous seed extract of Picralima nitida (APN) on dyslipidemia, hyperglycemia, oxidative stress, insulin resistance, and the expression of some metabolic genes in high-fat high-fructose-fed rats. Experimental rats ( 2 months old) were fed a control diet or a high-fat diet with $25 \%$ fructose (HFHF diet) in their drinking water for nine weeks. APN was administered orally during the last four weeks. Anthropometric and antioxidant parameters, lipid profile, plasma glucose, and insulin levels and the relative expression of some metabolic genes were assessed. APN caused a significant decrease $(P<0.05)$ in weight gained, body mass index, insulin resistance, plasma glucose, and insulin levels. Highdensity lipoprotein cholesterol level was significantly increased $(P<0.05)$, while triacylglycerol, cholesterol, low-density lipoprotein, cardiac index, atherogenic index, coronary artery index, and malondialdehyde levels in plasma and liver samples were also significantly decreased $(P<0.05)$ by APN at all experimental doses when compared to the group fed with an HFHF diet only. APN also significantly $(P<0.05)$ upregulated the relative expression of glucokinase, carnitine palmitoyltransferase-1 $(\mathrm{CPT}-1)$, and leptin at $400 \mathrm{mg} / \mathrm{kg}$ body weight when compared to the group fed with an HFHF diet only. This study showed that APN alleviated dyslipidemia, hyperglycemia, and oxidant effect associated with the intake of a high-fat high-fructose diet.
\end{abstract}

\section{Introduction}

Worldwide prevalence of various metabolic and cardiovascular disorders is still a major concern among health practitioners and researchers today $[1,2]$. Metabolic syndrome categorized by a group of interrelated metabolic, clinical, and biochemical features has been shown to increase the susceptibility of an individual to cardiovascular disease and type 2 diabetes (T2DM). These features include increased weight gained, waist circumference, hyperglycemia, insulin resistance, and dyslipidemia [3-6]. In Africa, the incidence of metabolic syndrome is as high as $50 \%$, depending on the population and the criteria used [7]. A recent study showed that the prevalence of metabolic syndrome among patients with type 2 diabetes was $59.62 \%$ in sub-Saharan Africa [8]. This is in contrast to what was obtainable in ancient times. A shift from the regular African/traditional diet to a western diet coupled with inadequate physical activity among several other factors might be responsible for the increasing rate of metabolic syndrome in Africa $[1,7,9]$. One major dietary lifestyle linked to metabolic syndrome and several cardiovascular disorders is the intake of high calorie-containing food [10]. This state of high-calorie malnutrition also results in oxidative stress $[11,12]$ which is a pathophysiological state characterized by a disparity in the number of antioxidants and oxidants 
produce in biological systems with the disparity favoring the oxidants [13].

Treatment and management of metabolic syndrome usually involve tackling all of the various risk factors classified under it. The focus is to prevent the progression of the risk factors to more complicated diseases [14, 15]. Several studies have shown the importance of plant-based food and botanicals in the treatment and management of metabolic syndrome caused by increased calorie intake [16-19].

Picralima nitida is a medicinal plant from the genus Picralima and plant family Apocynaceae. It is found in tropical African countries such as Ivory Coast, Nigeria, Uganda, and Gabon, and it is popularly known as Abeere in the Southwestern part of Nigeria among the Yoruba people [20-22]. The plant is used in traditional medicine for the treatment and management of malaria, abscesses, hepatitis, pneumonia, diabetes, and hypertension [21, 23]. The seeds are usually ground to a fine powder with the aid of a local grinder and added to foods [24] such as ogi (called pap in English) or taken as a decoction. Several studies have previously shown that various extracts of this plant are good sources of phytochemicals such as glycosides, alkaloids, triterpenes flavonoids, polyphenols, saponins, and tannins [23-29]. Alkaloids are the predominant bioactive compounds that have, so far, been isolated from the seeds of $P$. nitida [30]. Akuammicine, an indole alkaloid isolated from $P$. nitida, stimulated glucose uptake in differentiated 3T3-LI adipocytes. The report suggested that akuammicine could have acted singly or synergistically, with other bioactive compounds, to confer the accrued antidiabetic potential of the plant in folklore medicine [24]. Although few studies have corroborated the medicinal value of this plant, there is, however, a paucity of information on the scientific validation of the potential of this plant against high calorieinduced metabolic disorder and oxidative stress.

Hence, this present study examined the effect of aqueous seed extract of Picralima nitida (APN) on dyslipidemia, hyperglycemia, insulin resistance, and oxidative stress in high-fructose high-fat-fed rats.

\section{Materials and Methods}

2.1. Chemicals and Reagents. D-fructose was purchased from PhytoTechnology laboratories, Lenexa KS, The United States. A one-step RT-PCR kit (TransGen EasyScript ${ }^{\circledR}$ ) was purchased from TransGen Biotech Co. Ltd (Beijing, China). All other chemicals, unless stated otherwise, including nicotinamide adenine dinucleotide phosphate (NADPH), sulphanilamide, 1-chloro-2,4-dinitrobenzene (CDNB), xylenol, 5.5-dithio bis 2-nitrobenzoic acid (DTNB), bovine serum albumin (BSA), pyrogallol, HEPES, N-(1-naphthyl) ethylenediamine, and reduced glutathione (GSH) were purchased from Sigma-Aldrich, Germany.

2.2. Preparation of Aqueous Seed Extract of Picralima nitida. Picralima nitida seeds were collected fresh from local farms in Ota, Ogun State, Nigeria. The plant was identified and validated at the Forestry Research Institute of Nigeria,
Ibadan and specimen of the plant seed with voucher number FHI 111159 were deposited at the institute. The seeds were dehulled, air dried, crushed to powder using a blender, and extracted with distilled water for $72 \mathrm{~h}$ with a mass to volume ratio of $1: 5(\mathrm{~g} / \mathrm{L})$. The extract was dried under vacuum on a rotary evaporator at $55^{\circ} \mathrm{C}$ and stored at $4^{\circ} \mathrm{C}$ until use.

2.3. Laboratory Animals. Inbred male Wistar rats, Albinus, at two months old, were used in the study. The animals were made to adapt to the experimental and laboratory environmental conditions for two weeks in standard cages. The animals had free access to constant food and water and temperature in a reverse $12 \mathrm{~h}$ day/night cycle. The animals were maintained based on accepted guidelines following approval by the Covenant University Health Research Ethics Committee (CHREC/028/2018).

2.4. Experimental Design. All animals except the control animals (Group 1) were fed a high-fat diet (Table 1) with $25 \%$ fructose (HFHF) in their drinking water for 9 weeks. Blood glucose level was monitored via tail vein using AccuChek glucometer and Test Strip (Infopia Co., Ltd, South Korea), at 0, 2, 5, and 9 weeks. At the $5^{\text {th }}$ week, animals fed an HFHF diet and with a glucose level of $\geq 110 \mathrm{mg} / \mathrm{dl}$ were divided into four groups with one group (group 2) being fed an HFHF diet only throughout the experimental period. The other three groups, group 3, 4, and 5, were fed an HFHF diet throughout the experimental period with 100, 200, and $400 \mathrm{mg} / \mathrm{kg}$ body weight of Picralima nitida seed extract administered, respectively, via oral gavage during the last 4 weeks. The experimental doses were chosen based on a preliminary acute toxicity test which showed that the seed extract did not cause the death of experimental Wistar rats at 500,1000 , and $2000 \mathrm{mg} / \mathrm{kg}$ body weight. Also, from literature, the LD50 of various parts of the plant varied from $707.11 \mathrm{mg} / \mathrm{kg}$ to $14500 \mathrm{mg} / \mathrm{kg}$ with the highest LD50 value observed in experimental Wistar rats and the lowest in experimental mice [31-35]. Based on the fact that the LD50 is higher in Wistar rats, we decided to investigate the potential benefit of this plant at low to moderate doses.

2.5. Blood and Tissue Sampling. After 9 weeks, animals were weighed and anesthetized by intraperitoneal injection of $10 \mathrm{mg} / \mathrm{kg}$ of xylazine hydrochloride and $80 \mathrm{mg} / \mathrm{kg}$ of ketamine hydrochloride. Their length (nasal to anus length) and waist circumference was estimated using a standard measuring tape. Blood and tissue samples were prepared according to previously described methods [36].

2.6. Plasma Glucose and Insulin Level. Plasma glucose concentration was determined using the Randox glucose kit, Randox Laboratories Ltd, Crumlin, United Kingdom, while plasma insulin concentration was determined using Rat Insulin (INS) Enzyme-Linked Immunosorbent Assay (ELISA) kit, Hangzhou Eastbiopharma Co., Ltd, Hangzhou, China. The assays were carried out based on instructions outlined by the manufacturers. Insulin resistance was 
TABle 1: Feed and diet composition.

\begin{tabular}{lcc}
\hline & Control diet $(\mathrm{g} / \mathrm{kg})$ & HCHF $(\mathrm{g} / \mathrm{kg})$ \\
\hline Corn starch & 450 & 200 \\
Beef tallow & - & 250 \\
Sucrose & 100 & 100 \\
Cellulose & 100 & 100 \\
Soya bean oil & 70 & 70 \\
Fish meal & 240 & 240 \\
Vitamin and mineral mix $^{\mathrm{a}}$ & 40 & 40 \\
\hline
\end{tabular}

${ }^{a}$ Contained (per kg diet) vitamin A (4 $\left.000000 \mathrm{IU}\right)$, Vitamin D3 (8 00 $000 \mathrm{IU})$, vitamin E (8 $000 \mathrm{IU})$, vitamin $\mathrm{K} 3(0.9 \mathrm{~g})$, vitamin $\mathrm{B} 1$ (0.7 g), vitamin B2 $(2 \mathrm{~g})$, vitamin B6 $(1.2 \mathrm{~g})$ vitamin B12 $(0.006 \mathrm{~g})$, nicotinic acid $(11 \mathrm{~g})$, panthethoic acid $(3 \mathrm{~g})$ folic acid $(3 \mathrm{~g})$ biotin $(0.02 \mathrm{~g})$ choline $120 \mathrm{~g}$, $\mathrm{CuSO}_{4} \cdot 5 \mathrm{H}_{2} \mathrm{O}(2 \mathrm{~g}) \mathrm{CoCl}_{2} \cdot 6 \mathrm{H}_{2} \mathrm{O}(0.008), \mathrm{NaCl}(2 \mathrm{~g}), \mathrm{FeSO}_{4} \cdot 7 \mathrm{H}_{2} \mathrm{O}(8 \mathrm{~g}), \mathrm{KI}$ $(0.48 \mathrm{~g}), \mathrm{MnSO}_{4} \cdot 7 \mathrm{H}_{2} \mathrm{O}(32 \mathrm{~g}), \mathrm{CaSO}_{4}(14 \mathrm{~g})$, and $\mathrm{ZnSO}_{4}(20 \mathrm{~g})$.

evaluated using the homeostasis model assessment of basal insulin resistance (HOMA-IR) and calculated as reported previously [11].

2.7. Lipid Profile. Plasma levels of triglycerides (TAG), total cholesterol (TC), and high-density lipoprotein cholesterol (HDLc) were analyzed using readily available commercial kits, Randox Laboratories Ltd., Crumlin, United Kingdom. Low-density lipoprotein cholesterol (LDLc) was calculated as reported previously [37]. Cardiac index (CI), atherogenic index (AI), and coronary artery index (CAI) were calculated as reported by [11] using the formulae below:

$$
\begin{aligned}
\mathrm{CI} & =\frac{\mathrm{TC}}{\mathrm{HDLc}}, \\
\mathrm{AI} & =\frac{\mathrm{TC}-\mathrm{HDLc}}{\mathrm{HDLc}}, \\
\mathrm{CAI} & =\frac{\mathrm{LDLc}}{\mathrm{HDLc}} .
\end{aligned}
$$

2.8. Hepatic and Renal Function Assays. The activities of aspartate aminotransferase (ASP), alanine aminotransferase (ALT), alkaline phosphatase (ALP), and albumin levels in plasma samples were determined spectrophotometrically using Randox enzyme and albumin kits, Randox Laboratories Ltd, Crumlin, United Kingdom, based on instructions outlined in the manufacturer's guide. Urea and creatinine concentration in plasma and kidney homogenate samples were also assayed using Randox kit for urea and creatinine determination, Randox Laboratories Ltd., Crumlin, The United Kingdom.

2.9. Assessment of Oxidative Stress. The level of lipid peroxidation in plasma and liver homogenates was assessed by evaluating malondialdehyde (MDA) levels in samples using thiobarbituric acid reactive substances (TBARS) assay. Briefly, TBARS reagent $(1.0 \mathrm{ml})$ containing $0.25 \mathrm{~N} \mathrm{HCL}$, $0.375 \%$ of thiobarbituric acid, and $15 \%$ of trichloroacetic acid was added to $50 \mu \mathrm{l}$ of plasma and liver homogenate samples. The mixture was heated at boiling point for 15 minutes in a water bath, cooled on ice, and centrifuged at
$10,000 \mathrm{rpm}$ for $10 \mathrm{~min}$. The absorbance of the supernatant was recorded at $535 \mathrm{~nm}$ against a blank which contained all the reagents with distilled water replacing the samples. MDA levels were calculated from the extinction coefficient $\left(1.56 \times 10^{6}\right)$ of the MDA-TBA complex [38].

Reduced glutathione level in plasma and liver homogenates was assayed according to a previously described method [39]. Glutathione-s-transferase (GST) activity in plasma and liver homogenate samples was evaluated based on glutathione-s-transferase catalyzed reaction of reduced glutathione (GSH) with 1-chloro-2,4-dinitrobenzene (CDNB) to give a thioether (S-2,4-dinitrophenyl glutathione) which can be monitored by an increased change in absorbance at $340 \mathrm{~nm}$ [40]. Superoxide dismutase (SOD) activity was assayed based on the ability of the enzyme to prevent auto-oxidation of pyrogallol [41].

2.10. Total Protein Determination. The total protein level in plasma and liver homogenate samples was determined by a previously described method [42].

2.11. Extraction of RNA and mRNA Expression of Some Metabolic Genes. RNA was extracted from liver samples using TRIpure (Aidlab, Biotechnologies Ltd, Beijing, China) isolation reagent based on the instruction outlined in the manufacturer's guide. The level of expression of some metabolic genes was assessed according to a previously described method [36]. Briefly, Easyscript one-step RT-PCR supermix kit (TransGen Biotech Co., Ltd., Beijing, China) was used for the semiquantitative process based on the manufacturer's instruction. cDNA was first synthesized by incubating the RNA template $(500 \mathrm{ng})$ at $45^{\circ} \mathrm{C}$ for 30 minutes. A thermal cycler (C100 Touch thermal cycler, Bio-rad Laboratories) was used to carry out the amplification process using gene-specific primers as listed in Table 2. The PCR conditions included an initial denaturation at $94^{\circ} \mathrm{C}$ for 5 minutes, followed by 45 cycles of $94^{\circ} \mathrm{C}$ for 30 seconds, another 30 seconds at an annealing temperature of gene-specific primers and $1 \mathrm{~min}$ at $72^{\circ} \mathrm{C}$. The PCR products were run on an ethidium bromidestained agarose gel (1.5\%) in Tris Borate EDTA buffer and viewed under UV light (UVP BioDoc-It ${ }^{\mathrm{TM}}$ Imaging system (Upland, CA, USA). The intensity of the bands was analyzed using Image J software [43]. Results are expressed as the mean ratio of the intensity of each gene to that of two reference genes (GAPDH and $\beta$-actin).

2.12. Statistical Analysis. Data generated were analyzed using statistical package for the social sciences (SPSS) (ver. 20.0, SPSS Inc., Chicago, IL, USA) and results were represented as mean \pm SEM of at least five biological replicates. The level of heterogeneity among groups was assessed at $P<0.05$ by one-way analysis of variance (ANOVA) followed by Duncan's multiple range test.

\section{Results}

3.1. Food Intake, Water Intake, and Effect of APN on Anthropometric Data, Plasma Glucose, and Insulin Level. 
TABLE 2: Sequences of gene-specific primers.

\begin{tabular}{|c|c|c|}
\hline Gene & Sequence $\left(5^{\prime}-3^{\prime}\right)$ & Template \\
\hline GAPDH & $\begin{array}{l}\text { Forward AGTGCCAGCCTCGTCTCATA } \\
\text { Reverse GATGGTGATGGGTTTCCCGT }\end{array}$ & NM_017008.4 \\
\hline$\beta$-Actin & $\begin{array}{l}\text { Forward: GTCAGGTCATCACTATCGGCAAT } \\
\text { Reverse: AGAGGTCTTTACGGATGTCAACGT }\end{array}$ & NM_031144.3 \\
\hline GK & $\begin{array}{c}\text { Forward: CATATGTGCTCCGCAGGACTA } \\
\text { Reverse: CTTGTACACGGAGCCATCCA }\end{array}$ & NM_001270850.1 \\
\hline PEPCK & $\begin{array}{l}\text { Forward: AGCCTCGACAGCCTGCCCCAGG } \\
\text { Reverse: CCAGTTGTTGACCAAAGGCTTT }\end{array}$ & NM_198780.3 \\
\hline HMG-COA reductase & $\begin{array}{l}\text { Forward: TGCTGCTTTGGCTGTATGTC } \\
\text { Reverse: TGAGCGTGAACAAGAACCAG }\end{array}$ & NM_013134.2 \\
\hline $\mathrm{CPT}-1 \alpha$ & $\begin{array}{l}\text { Forward: AAGTCAACGGCAGAGCAGAG } \\
\text { Reverse: ACGCCCAAGTATTCACAGGG }\end{array}$ & NM_031559.2 \\
\hline Leptin & $\begin{array}{l}\text { Forward: GCCAAGGCAAACCCATTCTG } \\
\text { Reverse: GATACCGACTGCGTGTGTGA }\end{array}$ & XM_008762762.2 \\
\hline
\end{tabular}

GAPDH = Glyceraldehyde 3-phosphate dehydrogenase; GK = glucokinase; PEPCK= Phosphoenolpyruvate carboxykinase; HMG-COA reductase =3-hydroxy-3-methyl-glutaryl-coenzyme A reductase; CPT- $1 \alpha=$ carnitine palmitoyltransferase $1 \alpha$

Findings from this study showed that the group fed the control diet had increased mean daily food and water intake when compared with those fed an HFHF diet only. Despite this, rats fed with the HFHF diet had increased weight gained, body mass index (BMI), and lee index after 9 weeks. APN, however, significantly reduced $(P<0.05)$ weight gained and BMI at all the experimental dose used in this study when compared to those fed with HFHF diet only (Table 3). This reduction was, however, not significant when compared to the control group.

Fasting plasma glucose and insulin levels of the group fed an HFHF diet only was significantly increased when compared to those fed the control diet (Table 3). APN significantly reduced $(P<0.05)$ the effect of HFHF diet on plasma glucose concentration at all the doses used in this study while plasma insulin level, on the other hand, was significantly reduced $(P<0.05)$ at $100 \mathrm{mg} / \mathrm{kg}$ body weight of APN. There was, however, no significant difference in plasma glucose and insulin concentrations among the groups fed an HFHF diet and treated with APN when compared to the control group (Table 3).

Insulin resistance calculated based on homeostasis model assessment was found to increase significantly $(P<0.05)$ in HFHF-fed rats in comparison with those fed the control diet. APN significantly reduced insulin resistance at the various doses of the extracts. There was, however, no significant difference in insulin resistance among the treated groups administered APN when compared to the groups fed with only the control diet (Table 3).

3.2. Effect of APN on Lipid Profile. Plasma HDL levels of the group fed an HFHF diet, in comparison to the control group, were significantly decreased $(P<0.05)$. APN, at all experimental doses, ameliorated the effect of the HFHF diet by causing a significant increase $(P<0.05)$ in HDL levels. The ameliorative effect was dose-dependent (Figure 1).

Triacylglycerol, total cholesterol, and LDL cholesterol levels of rats fed an HFHF diet were significantly increased $(P<0.05)$ when compared to those fed a control diet
(Figure 1). Coronary artery index, cardiac index, atherogenic index, and coronary artery index of the group fed the HFHF diet were also significantly increased $(P<0.05)$ when compared to those fed with the control diet (Figure 2). APN significantly reduced $(P<0.05)$ total cholesterol and LDL cholesterol levels of HFHF-fed rats at all experimental doses of the extract used in this study (Figure 1). Triglyceride levels were also reduced. The reduction was, however, only significant $(P<0.05)$ at the highest administered dose of APN. APN also caused a significant reduction in cardiac index, atherogenic index, and coronary artery index at all experimental doses of APN when compared with the group fed the HFHF diet only (Figure 2).

3.3. Effect of APN on Hepatic and Renal Functions. Findings from this study also showed that in comparison with the group fed the control diet, ALP and ALT activities were significantly increased $(P<0.05)$ in the group fed an HFHF diet only. APN, however, significantly reduced ALP and ALT activities. There were no significant differences in plasma albumin, urea, plasma creatinine, and kidney creatinine levels of rats-fed with HFHF diet and treated with APN when compared with the control and HFHF-fed groups (Table 4).

3.4. Effect of APN on Lipid Peroxidation, GSH Level, GST, and SOD Activity. MDA levels increased significantly $(P<0.05)$ in plasma and liver homogenates of rats fed with an HFHF diet only when compared to those fed with the control diet (Figure 3). APN was, however, able to significantly $(P<0.05)$ reduce the oxidant effect of HFHF diet. APN also significantly increased $(P<0.05)$ the concentration of GSH in plasma and liver homogenates at $400 \mathrm{mg} / \mathrm{kg} \mathrm{BW}$ and $200 \mathrm{mg}$ $/ \mathrm{kg} \mathrm{BW}$, respectively, when compared to the group fed the control diet or HFHF diet (Figure 3). SOD activity in liver samples of the groups fed an HFHF diet and treated with different doses of APN was significantly increased when compared to those fed a control diet or HFHF diet only (Figure 4). 
TABLE 3: Effect of APN on weight gained, lee index, BMI, fasting plasma glucose and insulin level, and insulin resistance.

\begin{tabular}{|c|c|c|c|c|c|}
\hline & Control diet & HFHF diet & $\begin{array}{c}\mathrm{HFHF}+100 \mathrm{mg} / \mathrm{kg} \mathrm{BW} \\
\text { APN }\end{array}$ & $\begin{array}{c}\mathrm{HFHF}+200 \mathrm{mg} / \mathrm{kgBW} \\
\text { APN }\end{array}$ & $\begin{array}{c}\mathrm{HFHF}+400 \mathrm{mg} / \mathrm{kgBW} \\
\mathrm{APN}\end{array}$ \\
\hline Food intake $(\mathrm{g})$ & $18.50 \pm 0.57$ & $14.93 \pm 0.69^{\#}$ & $12.30 \pm 0.69^{\#}$ & $12.33 \pm 1.04^{\#}$ & $13.25 \pm 1.11^{\#}$ \\
\hline $\begin{array}{l}\text { Water/high fructose } \\
(\mathrm{ml})\end{array}$ & $31.98 \pm 0.66$ & $22.97 \pm 1.10^{\#}$ & $20.62 \pm 1.21^{\#}$ & $21.03 \pm 1.11^{\#}$ & $22.33 \pm 1.31^{\#}$ \\
\hline $\begin{array}{l}\text { Weight gained at } 9 \\
\text { weeks }(\mathrm{g})\end{array}$ & $57.50 \pm 7.52$ & $70.33 \pm 5.36$ & $39.17 \pm 2.50^{*}$ & $42.80 \pm 3.95^{*}$ & $51.00 \pm 9.01^{*}$ \\
\hline BMI $\left(\mathrm{g} / \mathrm{cm}^{2}\right)$ & $0.55 \pm 0.02$ & $0.65 \pm 0.02^{\#}$ & $0.57 \pm 0.02^{*}$ & $0.52 \pm 0.01^{*}$ & $0.54 \pm 0.02^{*}$ \\
\hline Lee index & $0.294 \pm 0.006$ & $0.313 \pm 0.005$ & $0.314 \pm 0.013$ & $0.294 \pm 0.05$ & $0.299 \pm 0.007$ \\
\hline Plasma glucose $(\mathrm{mmol} / \mathrm{l})$ & $7.57 \pm 1.05$ & $11.15 \pm 0.58^{\#}$ & $6.80 \pm 0.63^{*}$ & $7.16 \pm 0.48^{*}$ & $6.37 \pm 1.07^{*}$ \\
\hline Insulin level (mlU/L) & $7.78 \pm 1.21$ & $10.53 \pm 0.61^{\#}$ & $7.37 \pm 1.16^{*}$ & $9.62 \pm 0.21$ & $9.59 \pm 0.51$ \\
\hline HOMA-IR & $2.77 \pm 0.64$ & $5.40 \pm 0.56^{\#}$ & $2.13 \pm 0.29^{*}$ & $3.09 \pm 0.20^{*}$ & $2.66 \pm 0.38^{*}$ \\
\hline
\end{tabular}

Values are represented as mean \pm SEM. Values on the same row with \# are significantly $(P<0.05)$ different from control while those with * are significantly different $(P<0.05)$ from the HFHF-fed group.

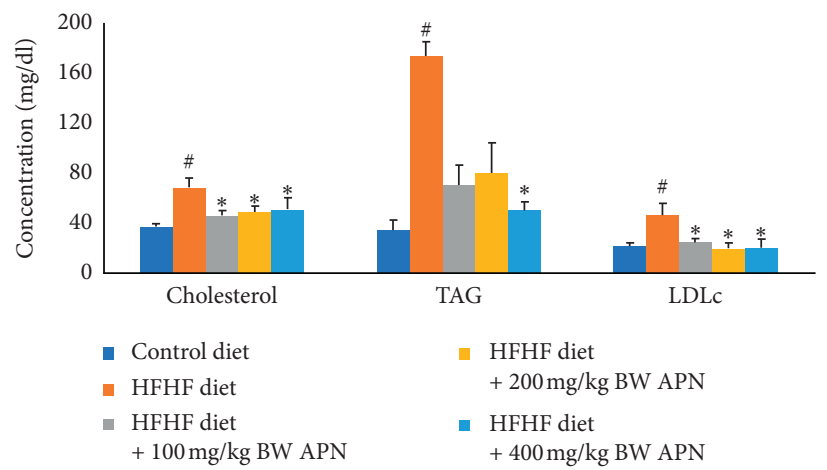

FIgURE 1: Effect of APN on cholesterol, triacylglycerol, and low-density lipoprotein cholesterol of rats fed an HFHF diet. Values are represented as mean \pm SEM of at least five biological replicates. Bars with \# are significantly $(P<0.05)$ different from control while bars with * are significantly different $(P<0.05)$ from HFHF-fed group.

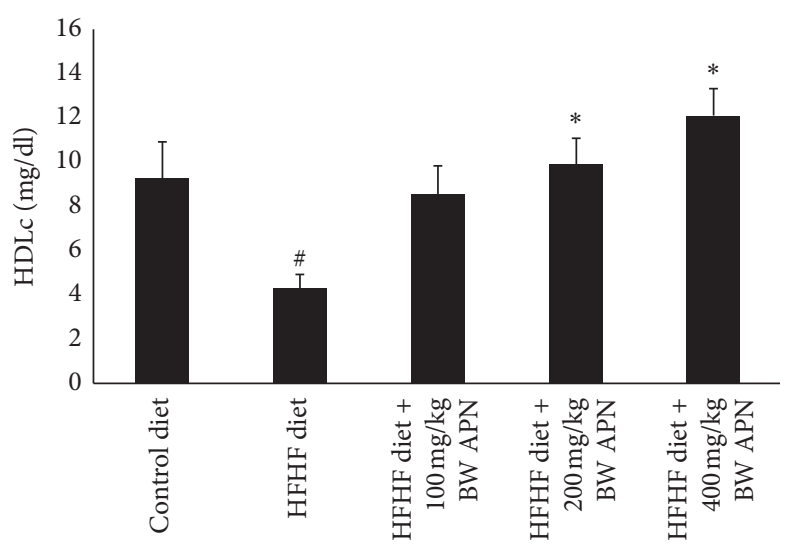

FIGURE 2: Effect of APN on HDLc of rats fed an HFHF diet. Values are represented as mean \pm SEM of at least five biological replicates. Bars with \# are significantly $(P<0.05)$ different from control while bars with ${ }^{*}$ are significantly different $(P<0.05)$ from HFHF-fed group.

3.5. Effect of APN on the Relative Expression of Some Metabolic Genes. The relative expression of genes coding for HMG-COA reductase, glucokinase, phosphoenolpyruvate carboxykinase (PEPCK), leptin, and carnitine palmitoyltransferase 1 were assessed in the liver of control and all treatment groups (Figure 4). The result showed that consumption of the HFHF diet led to a $35 \%$ and a $16 \%$ increase in the relative expressions of HMG-COA reductase and PEPCK when compared to those fed the control diet. APN, however, downregulated the expression of HMG-COA reductase at all experimental doses used in this study (Figure 4). The relative expression of glucokinase and carnitine palmitoyltransferase-1 (CPT-1) was significantly $(P<0.05)$ downregulated in the group fed an HFHF diet when compared to those fed the control diet. APN, however, significantly upregulated the expression of glucokinase at 100 and $400 \mathrm{mg} / \mathrm{kg}$ body weight while the relative 
TABLE 4: Effect of APN on the liver and kidney function.

\begin{tabular}{lccccc}
\hline & Control diet & HFHF diet & $\begin{array}{c}\text { HFHF }+100 \mathrm{mg} / \mathrm{kg} \text { BW } \\
\text { APN }\end{array}$ & $\begin{array}{c}\text { HFHF + 200 mg/kgBW } \\
\text { APN }\end{array}$ & $\begin{array}{c}\text { HFHF + 400 mg/kgBW } \\
\text { APN }\end{array}$ \\
\hline Liver weight (g) & $7.25 \pm 0.28$ & $8.23 \pm 0.53$ & $7.08 \pm 0.71$ & $6.27 \pm 0.14^{*}$ & $6.75 \pm 0.43^{*}$ \\
Kidney weight (g) & $2.57 \pm 0.31$ & $2.76 \pm 0.17$ & $2.90 \pm 0.31$ & $2.90 \pm 0.23$ & $2.40 \pm 0.18$ \\
Total protein (mg/ml) & $55.67 \pm 0.76$ & $73.31 \pm 2.52$ & $68.80 \pm 3.63$ & $64.64 \pm 5.76$ & $83.65 \pm 6.23^{\#}$ \\
ALP (U/l) & $117.76 \pm 10.78$ & $150.88 \pm 22.17$ & $111.09 \pm 8.80$ & $74.70 \pm 8.69^{*}$ & $84.64 \pm 6.46^{*}$ \\
AST (U/l) & $25.04 \pm 0.48$ & $34.32 \pm 1.33$ & $24.46 \pm 3.11$ & $30.76 \pm 4.60$ & $29.39 \pm 5.38$ \\
ALT (U/l) & $41.43 \pm 2.95$ & $62.94 \pm 4.26^{\#}$ & $26.80 \pm 5.57$ & $17.81 \pm 1.75^{*} \#$ & $18.82 \pm 0.85^{*} \#$ \\
Albumin (U/l) & $4.63 \pm 0.16$ & $4.01 \pm 0.16$ & $5.09 \pm 0.54$ & $4.64 \pm 0.47$ & $3.82 \pm 0.58$ \\
Plasma urea (mg/dl) & $61.87 \pm 1.75$ & $62.69 \pm 4.24$ & $70.69 \pm 5.14$ & $65.33 \pm 2.64$ & $69.39 \pm 3.51$ \\
Kidney urea (mg/dl & $32.87 \pm 4.21$ & $42.29 \pm 4.85$ & $50.04 \pm 6.54$ & $52.70 \pm 6.37^{\#}$ & $49.69 \pm 2.64$ \\
Plasma creatinine & $3.64 \pm 0.19$ & $3.63 \pm 0.51$ & $3.33 \pm 0.23$ & $3.41 \pm 0.21$ & $3.17 \pm 0.07$ \\
(mg/dl) & & & & \\
Kidney creatinine & $2.45 \pm 0.21$ & $2.31 \pm 0.30$ & $2.18 \pm 0.13$ & $1.97 \pm 0.14$ & $2.80 \pm 0.85$ \\
(mg/dl) & & &
\end{tabular}

Values are represented as mean \pm SEM. Values on the same row with ${ }^{\#}$ are significantly $(P<0.05)$ different from control while those with ${ }^{*}$ are significantly different $(P<0.05)$ from HFHF-fed group.

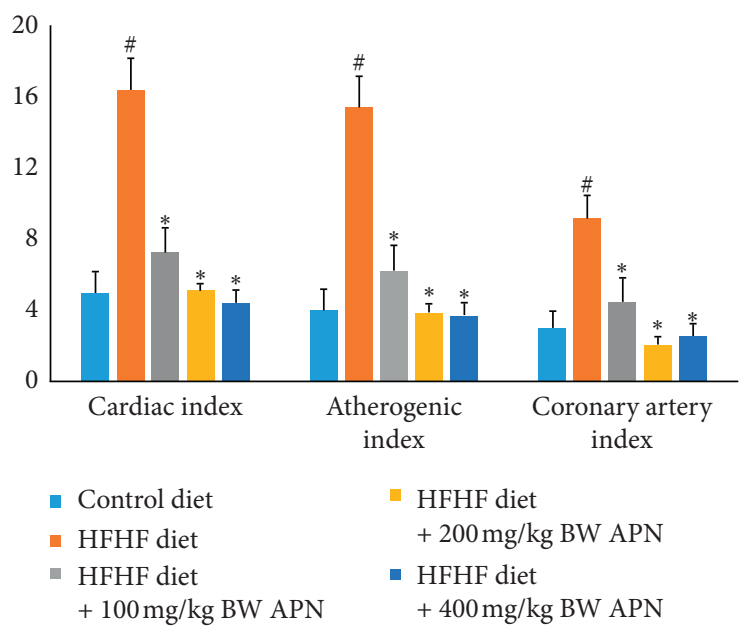

FIGURE 3: Effect of APN on the cardiac index, atherogenic index, and coronary artery index of rats fed an HFHF diet. Values are represented as mean \pm SEM of at least five biological replicates. Bars with \# are significantly $(P<0.05)$ different from control while bars with ${ }^{*}$ are significantly different $(P<0.05)$ from HFHF-fed group.

expression of CPT-1 was only significantly upregulated at $400 \mathrm{mg} / \mathrm{kg}$ body weight of APN (Figure 4). The relative expression of leptin was downregulated by $39 \%$ in rats fed an HFHF diet when compared to those fed the control diet. APN, however, upregulated the expression when compared to the control group (Figure 5).

\section{Discussion}

The increasing prevalence of metabolic-related disorders and the morbidity and mortality associated with them has spurred a growing interest in identifying and validating botanicals that can help stem the tide. This research work investigated the potential palliative role of aqueous seed extract of Picralima nitida on weight gained, lee index, BMI, hyperglycemia, dyslipidemia, and oxidative stress in rats fed a high fructose high-fat diet. Weight gained, lee index, and body mass index (BMI) are common anthropometric measures of obesity used in most experimental rodents studies [44]. Although rats fed an HFHF diet only had decreased mean daily food and water intakes, they gained more weight and had higher BMI, plasma fasting insulin and glucose levels than those fed the control diet. Elevated plasma glucose and insulin observed among the group fed only an HFHF diet suggest a state of insulin insensitivity which could result from the inability of muscle and liver cells to take up glucose. Dyslipidemia characterized by an increase in TAG, TC and LDLc followed by a decrease in HDLc levels was also observed among the group fed an HFHF diet only. These metabolic modifications observed in this study substantiated the claim in experimental models that high calorie-containing foods cause glucose levels to rise in the blood, insulin insensitivity and dyslipidemia all of which increases the development of cardiovascular related disorders [11, 16, 45-49]. The ability of APN to reduce plasma glucose levels is in line with previous studies that showed its hypoglycemic effect in vitro and in vivo $[23,31,35,50]$. Also, the capability of the plant extract to reduce the weight gained and body mass index shows its antiobesity potential while its ability to reduce cholesterol, 


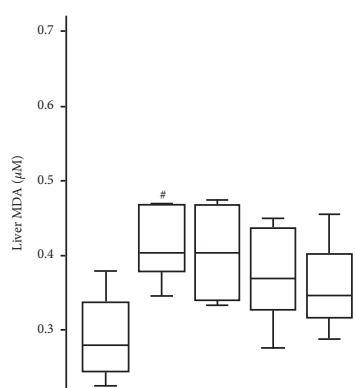

(a)

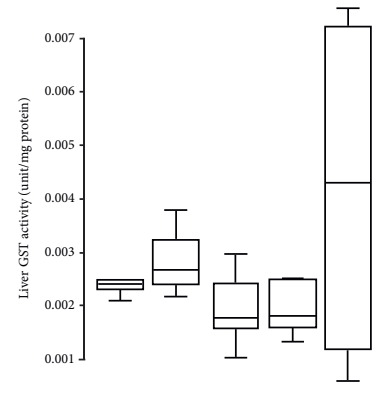

(e)

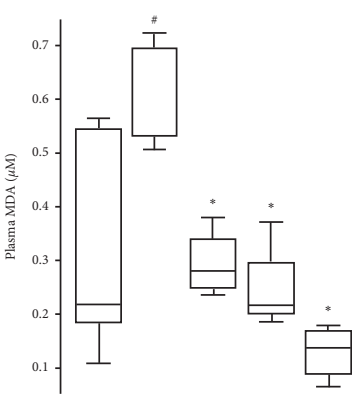

(b)

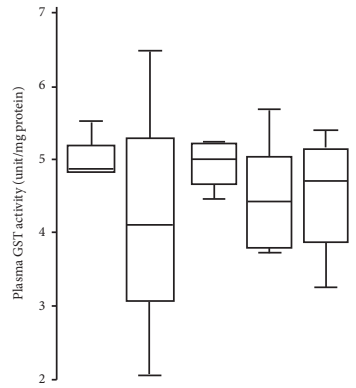

(f)

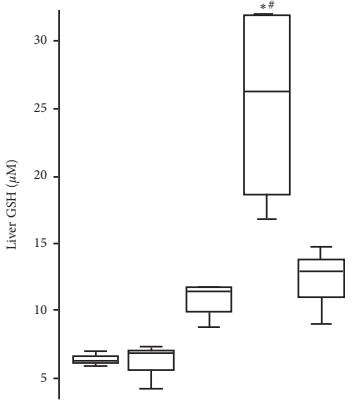

(c)

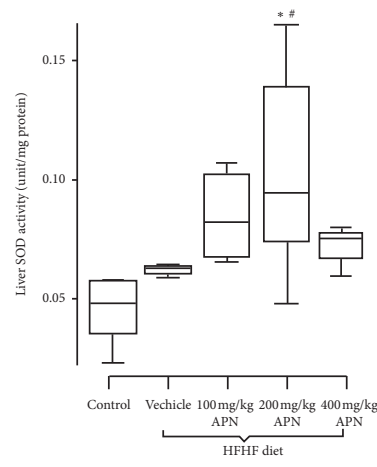

(g)

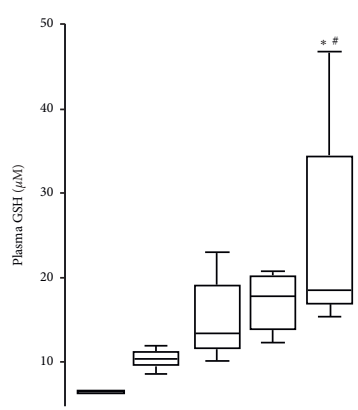

(d)

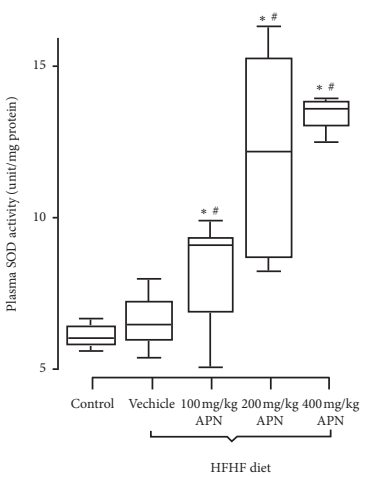

(h)

FIGURE 4: Effect of APN on MDA concentration and antioxidant parameters of rats fed an HFHF diet. (a) MDA level in liver homogenates; (b) MDA level in plasma samples; (c) GSH level in liver homogenates; (d) GSH level in plasma samples; (e) GST activity in liver homogenates; (f) GST activity in plasma; (g) SOD activity in liver homogenates; (h) SOD activity in plasma samples Bars with \# are significantly $(P<0.05)$ different from control while bars with ${ }^{*}$ are significantly different $(P<0.05)$ from HFHF-fed group.

triacylglycerol, and LDLc while increasing HDLc show its antidyslipidemic action and suggests that the plant could offer protective action against cardiovascular diseases.

The expression of some carbohydrate and lipid metabolizing enzymes in the liver of all treatment groups was also examined. Findings from this study showed that consumption of HFHF diet caused a downregulation of the expression of hepatic glucokinase and a mild upregulation of phosphoenolpyruvate carboxykinase when compared to that of the control. In the liver, glucokinase plays a critical catalytic role by promoting the addition of a phosphate group to glucose, thereby enhancing its uptake in the liver $[51,52]$. Phosphoenolpyruvate carboxykinase, on the other hand, is a crucial enzyme in the gluconeogenesis pathway that helps to increase glucose production [53]. Reduced expression of glucokinase in the liver may be a result of the elevated plasma glucose concentration observed in rats fed an HFHF diet only indicating an inability to promote glucose uptake in the liver despite elevated insulin levels. APN, however, helped to upregulate the expression of glucokinase at 100 and $400 \mathrm{mg} / \mathrm{kg}$ body weight, demonstrating that APN can increase the expression of glucokinase and thus promote glucose uptake by the liver. Activators of glucokinase have been shown to be important in the treatment of diabetes $[52,54]$. The mRNA expression level of carnitine palmitoyltransferase $1 \alpha(\mathrm{CPT}-1 \alpha)$, an important enzyme that aids the transport of long-chain free fatty acids into the mitochondria where they undergo $\beta$-oxidation, has been shown to decrease in experimental rodents fed a highfat diet, high fructose diet, or high-fat high fructose combined diet [53, 55-57]. Conversely, mRNA expression of HMG-COA reductase, a rate-limiting enzyme of the cholesterol biosynthetic pathway, has been reported to increase following the consumption of a high-fat diet in rats $[58,59]$. These reports corroborate findings from this study which indicated that intake of a high fructose high-fat diet caused a significant downregulation of the expression of CPT- $1 \alpha$ while causing an upregulation in the expression levels of HMG-COA reductases. The aqueous seed extract of Picralima nitida, however, modulates the expression levels of these lipid metabolizing genes by downregulating the expression of HMG-COA- reductase at all experimental doses and upregulating the expression of CPT- $1 \alpha$ at the highest dose of the extract. Surprisingly relative expression of leptin was downregulated in rats fed an HFHF diet when compared to the control group. APN, however, upregulated the relative expression of leptin at $400 \mathrm{mg} / \mathrm{kg}$ body weight. Although leptin is known to promote satiety, in the liver, it is known to prevent the synthesis of fat while promoting the breakdown of fatty acids [60].

Intake of high-fat high fructose diet has also been linked to hepatic dysfunction characterized by elevated levels of plasma ALT, AST, and ALP $[19,45,61,62]$. Similarly, results from this study showed consumption of an HFHF diet caused a significant increase in plasma ALT and ALP levels when compared to the control diet. These enzymes are 


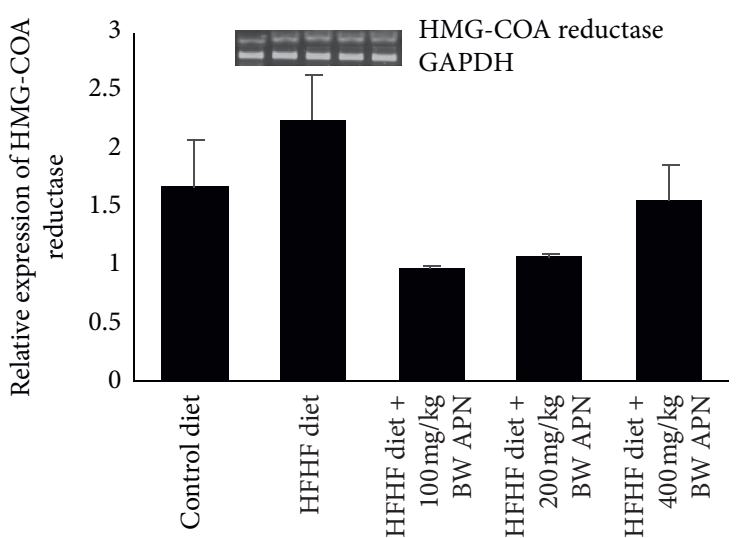

(a)

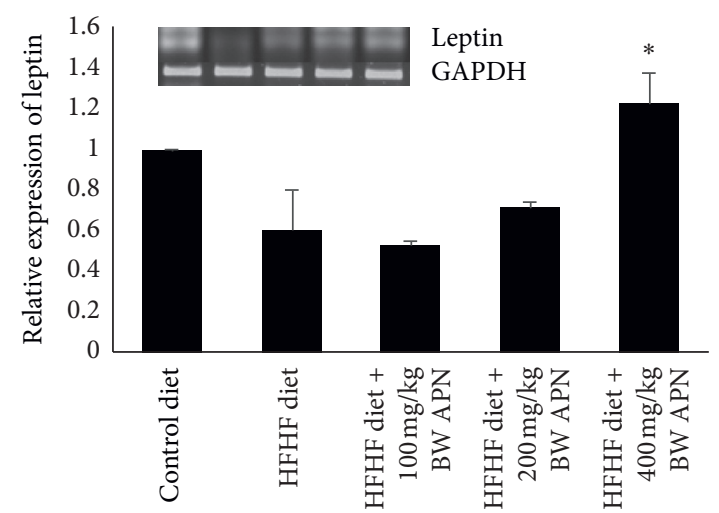

(c)

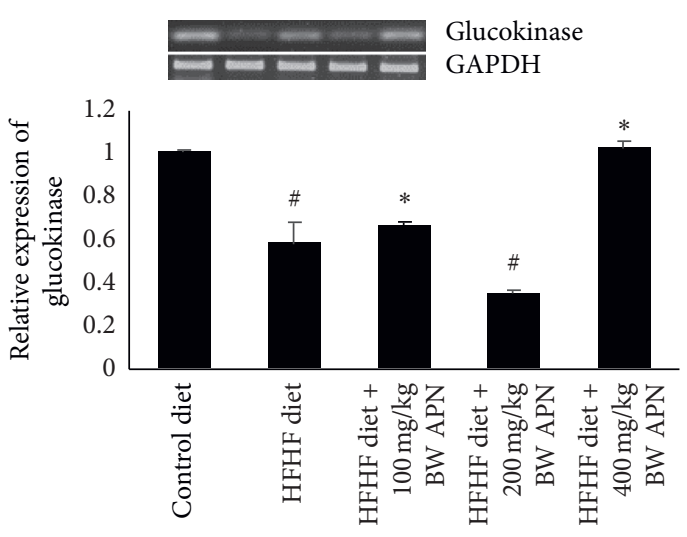

(b)

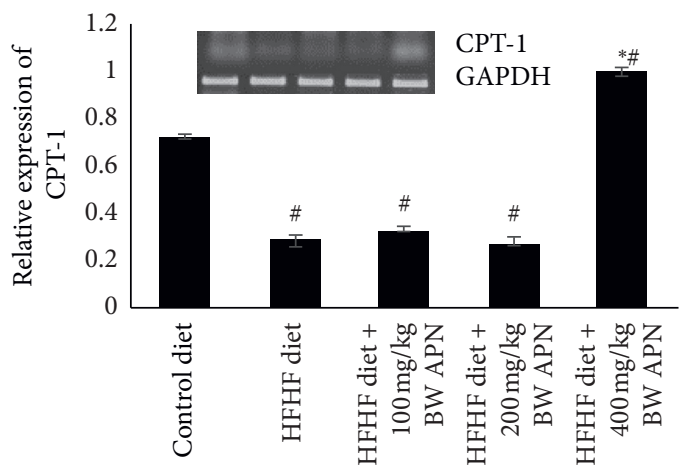

(d)

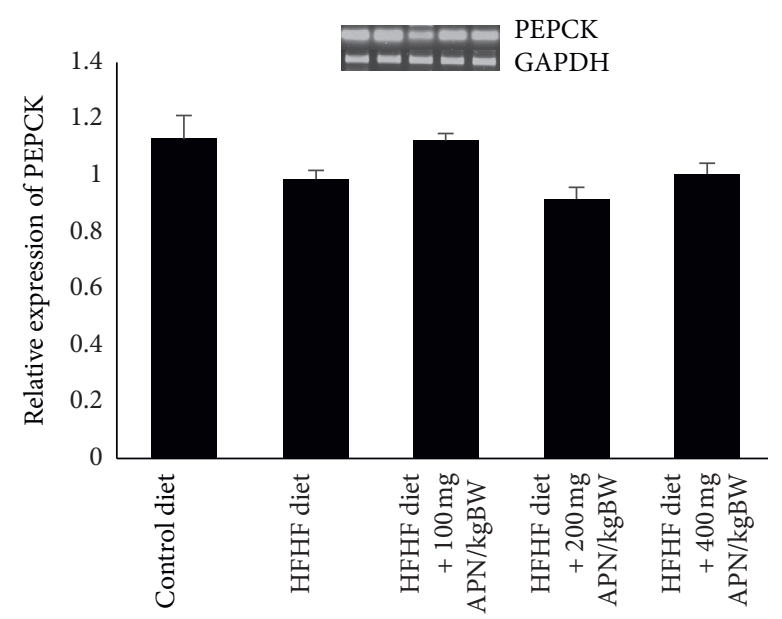

(e)

FIGURE 5: Effect of APN on the relative expression of some metabolic genes. (a) Relative expression of HMG-COA reductase; (b) relative expression of glucokinase; (c) relative expression of leptin; (d) relative expression of CPT-1; (e) relative expression of PEPCK. $\beta$-Actin and GAPDH were used as the reference gene to calculate the relative expression of the genes. Bars with ${ }^{\#}$ are significantly $(P<0.05)$ different from control while bars with ${ }^{*}$ are significantly different $(P<0.05)$ from HFHF-fed group.

critical hepatic enzymes that leak into the bloodstream when the liver is damaged or injured and have served as critical biomarkers for assessing hepatic dysfunction. APN, however, significantly decreases the plasma level of these enzymes emphasizing its hepatoprotective potential.

Several reports have also shown a strong correlation between features of metabolic syndrome and oxidative stress $[13,61,63,64]$. It is well-known that a high intake of fat- and carbohydrate-containing food coupled with an inactive lifestyle creates an imbalance in the energy status of the body $[65,66]$. This often leads to an elevated amount of glucose in the blood, which are often stored as fats in the adipose tissues [64]. An elevated level of lipids/fats causes a cascade of reactions that promotes the formation of lipid peroxides via the process of lipid peroxidation, which are highly reactive and ultimately damage cells and tissues [67]. The level of 
lipid peroxidation in most biological samples is usually assessed by determining the malondialdehyde level (MDA) in such samples. This study, like previous studies [19, 48], showed that rats fed an HFHF had elevated levels of malondialdehyde in liver homogenates and plasma samples when compared to those fed the control diet. The ability of APN to cause a reduction in MDA level can be attributed to its antihyperlipidemic action as observed in this study.

Interestingly, APN also significantly increased GSH level and SOD activity in plasma and liver samples, suggesting a protective action of the plant against reactive oxygen species. GSH is a nonenzymatic antioxidant and a major low molecular weight thiol in most animal cells [68]. It plays a critical role, directly or indirectly, in scavenging reactive oxygen and nitrogen species. SOD, on the other hand, is an essential antioxidant enzyme that helps in neutralizing the harmful effect of superoxide ion by converting it to oxygen and hydrogen peroxide [69].

Although this study did not focus on the bioactive compounds present in this plant, several studies have previously shown that various extracts of this plant are good sources of phytochemicals [26, 27, 30, 33, 70]. More specifically, the seed extract of the $P$. nitida has been reported to contain glycosides, alkaloids, triterpenes flavonoids, polyphenols, saponins, and tannins $[31,33,35]$. Akuammicine, indole alkaloid isolated from the seeds of $P$. nitida, was reported to be effective in stimulating glucose uptake in differentiated 3T3-LI adipocytes [24]. The protective role of the APN observed in this study can thus be attributed to the phytochemicals present in the plant. These compounds may act singly or synergistically to confer their effects.

\section{Conclusions}

In conclusion, this study showed that APN alleviated dyslipidemia, hyperglycemia, and pro-oxidant status associated with the intake of a high-fat high fructose diet.

\section{Data Availability}

All data have been included in the article.

\section{Conflicts of Interest}

The authors declare no conflicts of interest.

\section{Authors' Contributions}

OCD, SOR, and SNC developed the idea; OCD, TIB, DIO, and FNI carried out the experiment; OCD and SOR analyzed the result. OCE wrote the manuscript; SOR, SNC, and FNI reviewed and edited the manuscript.

\section{Acknowledgments}

The authors acknowledge Covenant University for the payment of the article processing charge of this research article through Covenant University Center for Research, Innovation, and Discovery.

\section{References}

[1] M. G. Saklayen, "The global epidemic of the metabolic syndrome," Current Hypertension Reports, vol. 20, no. 2, 2018.

[2] G. A. Roth, C. Johnson, A. Abajobir et al., "Global, regional, and national burden of cardiovascular diseases for 10 causes, 1990 to 2015," vol. 70, no. 1, pp. 1-25, 2017.

[3] D. L. Mendrick, A. M. Diehl, L. S. Topor et al., "Metabolic syndrome and associated diseases: from the bench to the clinic," Toxicological Sciences, vol. 162, no. 1, pp. 36-42, 2018.

[4] S. M. Grundy, "Metabolic syndrome update," Trends in Cardiovascular Medicine, vol. 26, no. 4, pp. 364-373, 2016.

[5] E. McCracken, M. Monaghan, and S. Sreenivasan, "Pathophysiology of the metabolic syndrome," Clinics in Dermatology, vol. 36, no. 1, pp. 14-20, 2018.

[6] R. H. Eckel, K. Alberti, S. M. Grundy, and P. Z. Zimmet, "The metabolic syndrome," The Lancet, vol. 375, no. 9710, pp. 181-183, 2010.

[7] C. Okafor, "The metabolic syndrome in Africa: current trends," Indian Journal of Endocrinology and Metabolism, vol. 16, no. 1, p. 56, 2012.

[8] W. S. Shiferaw, T. Y. Akalu, M. Gedefaw et al., "Metabolic syndrome among type 2 diabetic patients in Sub-Saharan African countries: a systematic review and meta-analysis," Diabetes \& Metabolic Syndrome: Clinical Research \& Reviews, vol. 14, no. 5, pp. 1403-1411, 2020.

[9] T. Mbogori and W. Mucherah, "Nutrition transition in Africa: consequences and opportunities," Global Journal of Transformative Education, vol. 1, no. 1, pp. 5-10, 2019.

[10] E. Rodríguez-Correa, I. González-Pérez, P. I. Clavel-Pérez, Y. Contreras-Vargas, and K. Carvajal, "Biochemical and nutritional overview of diet-induced metabolic syndrome models in rats: what is the best choice?" Nutrition \& Diabetes, vol. 10, no. 1, 2020.

[11] T. O. Ajiboye, H. O. Raji, A. O. Adeleye et al., "Hibiscus sabdariffacalyx palliates insulin resistance, hyperglycemia, dyslipidemia and oxidative rout in fructose-induced metabolic syndrome rats," Journal of the Science of Food and Agriculture, vol. 96, no. 5, pp. 1522-1531, 2016.

[12] K. Prasad and I. Dhar, "Oxidative stress as a mechanism of added sugar-induced cardiovascular disease," The International Journal of Angiology, vol. 23, no. 4, pp. 217-226, 2014.

[13] M. Monserrat-Mesquida, M. Quetglas-Llabrés, X. Capó et al., "Metabolic syndrome is associated with oxidative stress and proinflammatory state," Antioxidants, vol. 9, no. 3, p. 236, 2020.

[14] C.-Y. Chen, C.-W. Lee, S.-C. Chien et al., "Dyslipidemia management for elderly people with metabolic syndrome: a mini-review," International Journal of Gerontology, vol. 12, no. 1, pp. 7-11, 2018.

[15] J. Rask Larsen, L. Dima, C. U. Correll, and P. Manu, "The pharmacological management of metabolic syndrome," Expert Review of Clinical Pharmacology, vol. 11, no. 4, pp. 397-410, 2018.

[16] T. O. Ajiboye, A. A. Hussaini, B. Y. Nafiu, and O. B. Ibitoye, "Aqueous seed extract of Hunteria umbellata (K. Schum.) Hallier f. (Apocynaceae) palliates hyperglycemia, insulin resistance, dyslipidemia, inflammation and oxidative stress in high-fructose diet-induced metabolic syndrome in rats," Journal of Ethnopharmacology, vol. 198, pp. 184-193, 2017.

[17] M. Yavuz, S. Luin, G. Tamma et al., "Nanophytomedicines for the prevention of metabolic syndrome: a pharmacological and biopharmaceutical review," Frontiers in Bioengineering and Biotechnology, vol. 8, p. 425, 2020. 
[18] C.-C. Huang, Y.-T. Tung, W.-C. Huang, Y.-M. Chen, Y.-J. Hsu, and M.-C. Hsu, "Beneficial effects of cocoa, coffee, green tea, and garcinia complex supplement on diet induced obesity in rats," BMC Complementary and Alternative Medicine, vol. 16, no. 1, p. 100, 2016.

[19] H. Poudyal, F. Campbell, and L. Brown, "Olive leaf extract attenuates cardiac, hepatic, and metabolic changes in high carbohydrate-, high fat-fed rats," The Journal of Nutrition, vol. 140 , no. 5, pp. 946-953, 2010.

[20] O. U. Amaeze, R. I. Aderemi-Williams, M. A. Ayo-Vaughan, D. A. Ogundemuren, D. S. Ogunmola, and E. N. Anyika, "Herbal medicine use among type 2 diabetes mellitus patients in Nigeria: understanding the magnitude and predictors of use," International Journal of Clinical Pharmacy, vol. 40, no. 3, pp. 580-588, 2018.

[21] O. Erharuyi, A. Falodun, and P. Langer, "Medicinal uses, phytochemistry and pharmacology of Picralima nitida (Apocynaceae) in tropical diseases: a review," Asian Pacific Journal of Tropical Medicine, vol. 7, no. 1, pp. 1-8, 2014.

[22] O. A. Olajide, R. Velagapudi, U. P. Okorji, S. D. Sarker, and B. L. Fiebich, "Picralima nitida seeds suppress PGE2 production by interfering with multiple signalling pathways in IL- $1 \beta$-stimulated SK-N-SH neuronal cells," Journal of Ethnopharmacology, vol. 152, no. 2, pp. 377-383, 2014.

[23] C. M. Teugwa, P. C. Mejiato, D. Zofou, B. T. Tchinda, and F. F. Boyom, "Antioxidant and antidiabetic profiles of two African medicinal plants: Picralima nitida (Apocynaceae) and Sonchus oleraceus (Asteraceae)," BMC Complementary and Alternative Medicine, vol. 13, no. 1, p. 175, 2013.

[24] H. Shittu, A. Gray, B. Furman, and L. Young, "Glucose uptake stimulatory effect of akuammicine from Picralima nitida (Apocynaceae)," Phytochemistry Letters, vol. 3, no. 1, pp. $53-55,2010$.

[25] E. T. Idowu, H. C. Idowu, A. I. Omotayo, O. O. Aina, and O. A. Otubanjo, "In vivo anti-plasmodial activities and toxic impacts of lime extract of a combination of Picralima nitida, Alstonia boonei and Gongronema latifolium in mice infected with Chloroquine-sensitive Plasmodium berghei," African Health Sciences, vol. 15, no. 4, pp. 1262-1270, 2015.

[26] N. A. Obasi, U. C. Okorie, B. N. Enemchukwu, S. S. Ogundapo, and G. Otuchristi, "Nutritional evaluation, phytochemical screening and antimicrobial effects of aqueous extract of Picralima nitida peel," Asian Journal of Biological Sciences, vol. 5, no. 2, pp. 105-112, 2012.

[27] G. Dapaah, G. A. Koffuor, P. K. Mante, and I. O. Ben, "Antitussive, expectorant and analgesic effects of the ethanol seed extract of Picralima nitida (Stapf) Th. and H. Durand," Research in Pharmaceutical Sciences, vol. 11, no. 2, pp. 100112, 2016.

[28] NC. Loumpangou, G. Tsiba, J.-N. Koane et al., "Phytochemical screening and evaluation of the antioxidant activity of the polar extracts Picralima nitida Stapf. (Apocynaceae) family," Journal of Pharmacognosy and Phytochemistry, vol. 5, pp. 198-204, 2016.

[29] K. F. Akinwunmi and C. V. Amadi, "Assessment of antioxidant and antidiabetic properties of Picralima nitida seed extracts," Journal of Medicinal Plants Research, vol. 13, no. 1, pp. 9-17, 2019.

[30] C. F. Alcover, G. Bernadat, F. A. Kabran et al., "Molecular networking reveals serpentinine-related bisindole alkaloids from Picralima nitida, a previously well-investigated species," Journal of Natural Products, vol. 83, no. 4, pp. 1207-1216, 2020.
[31] S. Inya-Agha, S. Ezea, and O. Odukoya, "Evaluation of Picralima nitida hypoglycemic activity, toxicity and analytical standards," Planta Medica, vol. 72, no. 11, pp. 574-578, 2006.

[32] L. B. Kouitcheu Mabeku, J. Kouam, A. Paul, and F. X. Etoa, "Phytochemical screening and toxicological profile of methanolic extract of Picralima nitidafruit-rind (Apocynaceae)," Toxicological \& Environmental Chemistry, vol. 90, no. 4, pp. 815-828, 2008.

[33] A. Olufunsho, A. G. V. Coulidiaty, A. G. Oluyemi, A. Sunday, B. Omoseyindemi, and K. Busia, "Toxicological evaluation of Picralima nitida in rodents," Journal of Ethnopharmacology, vol. 236, pp. 205-219, 2019.

[34] F. KK. N'dri, S. A. Nene-Bi, O. S. Zahoui, and F. Traore, "Phytochemical and toxicological studies of an extract of the seeds of Picralima nitida (stapf) (apocynaceae) and its pharmacological effects on the blood pressure of rabbit," Journal of Biology and Life Science, vol. 6, p. 114, 2015.

[35] J. M. Okonta and C. N. Aguwa, "Evaluation of hypoglycemic activity of glycosides and alkaloids extracts of Picralima nitida stapf (Apocynaceae) seed," International Journal of Pharmacology, vol. 3, no. 6, pp. 505-509, 2007.

[36] S. O. Rotimi, G. E. Bankole, I. B. Adelani, and O. A. Rotimi, "Hesperidin prevents lipopolysaccharide-induced endotoxicity in rats," Immunopharmacology and Immunotoxicology, vol. 38, no. 5, pp. 364-371, 2016.

[37] W. T. Friedewald, R. I. Levy, and D. S. Fredrickson, "Estimation of the concentration of low-density lipoprotein cholesterol in plasma, without use of the preparative ultracentrifuge," Clinical Chemistry, vol. 18, no. 6, pp. 499-502, 1972.

[38] J. A. Buege and S. D. Aust, "Microsomal lipid peroxidation," Methods in Enzymology BiomembranesPart C: Biological Oxidations, vol. 52, pp. 302-310, 1978.

[39] M. Moron, J. Depierre, and B. Mannervik, "Levels of glutathione, glutathione reductase and glutathione S-transferase activities in rat lung and liver," Biochimica et Biophysica Acta (BBA)General Subjects, vol. 582, no. 1, pp. 67-78, 1979.

[40] W. H. Habig, M. J. Pabst, and W. B. Jakoby, "Glutathione Stransferases. The first enzymatic step in mercapturic acid formation," Journal of Biological Chemistry, vol. 249, no. 22, pp. 7130-7139, 1974, http://www.jbc.org/content/249/22/ 7130.full.pdf.

[41] S. Marklund and G. Marklund, "Involvement of the superoxide anion radical in the autoxidation of pyrogallol and a convenient assay for superoxide dismutase," European Journal of Biochemistry, vol. 47, no. 3, pp. 469-474, 1974.

[42] O. H. Lowry, N. J. Rosebrough, A. L. Farr, and R. J. Randall, "Protein measurement with the folin phenol reagent," The Journal of Biological Chemistry, vol. 193, no. 1, pp. 265-275, 1951.

[43] M. D. Abràmoff, P. J. Magalhães, and S. J. Ram, "Image Processing with ImageJ," vol. 11, pp. 36-42, Laurin Publishing Co. Inc., Pittsfield, MA, USA, 2nd edition, 2004.

[44] O. A. Rotimi, I. O. Olayiwola, O. Ademuyiwa, and E. A. Balogun, "Effects of fibre-enriched diets on tissue lipid profiles of MSG obese rats," Food and Chemical Toxicology, vol. 50, no. 11, pp. 4062-4067, 2012.

[45] SK. Panchal, H. Poudyal, A. Iyer et al., "High-carbohydrate high-fat diet-induced metabolic syndrome and cardiovascular remodeling in rats," Journal of Cardiovascular Pharmacology and Therapeutics, vol. 57, no. 1, pp. 51-64, 2011.

[46] G. Sangüesa, M. Baena, N. Hutter et al., "The addition of liquid fructose to a western-type diet in LDL-R-/- mice induces liver inflammation and fibrogenesis markers without 
disrupting insulin receptor signalling after an insulin challenge," Nutrients, vol. 9, no. 3, pp. 278-315, 2017.

[47] B. Ruiza G. Ang and G. F. Yu, "The role of fructose in type 2 diabetes and other metabolic diseases," Journal of Nutrition \& Food Sciences, vol. 8, no. 1, p. 659, 2018.

[48] K. Jarukamjorn, N. Jearapong, C. Pimson, and W. Chatuphonprasert, "A high-fat, high-fructose diet induces antioxidant imbalance and increases the risk and progression of nonalcoholic fatty liver disease in mice," Scientifica, vol. 2016, Article ID 5029414, 10 pages, 2016.

[49] M. C. Della Vedova, M. D. Muñoz, L. D. Santillan et al., “A mouse model of diet-induced obesity resembling most features of human metabolic syndrome," Nutrition and Metabolic Insights, vol. 9, pp. NMI.S32907-102, 2016.

[50] A. Yessoufou, J. Gbenou, O. Grissa et al., "Anti-hyperglycemic effects of three medicinal plants in diabetic pregnancy: modulation of T cell proliferation," BMC Complementary and Alternative Medicine, vol. 13, no. 1, p. 77, 2013.

[51] M. L. Massa, J. J. Gagliardino, and F. Francini, "Liver glucokinase: an overview on the regulatorymechanisms of its activity," IUBMB Life, vol. 63, no. 1, pp. 1-6, 2011.

[52] T. J. Guzmán and C. M. Gurrola-Díaz, "Glucokinase activation as antidiabetic therapy: effect of nutraceuticals and phytochemicals on glucokinase gene expression and enzymatic activity," Archives of Physiology and Biochemistry, pp. 1-12, 2019.

[53] A. Teofilović, B. Bursać, A. Djordjevic, G. Matić, and N. Veličković, "High dietary fructose load aggravates lipid metabolism in the liver of wistar rats through imbalance between lipogenesis and fatty acid oxidation," Turkish Journal of Biology, vol. 40, pp. 1235-1242, 2016.

[54] K. A. Toulis, K. Nirantharakumar, C. Pourzitaki, A. H. Barnett, and A. A. Tahrani, "Glucokinase activators for type 2 diabetes: challenges and future developments," Drugs, vol. 80, no. 5, pp. 467-475, 2020.

[55] H. Kang and S. Koppula, "Houttuynia cordataalleviates highfat diet-induced non-alcoholic fatty liver in experimental rats," Pharmaceutical Biology, vol. 53, no. 3, pp. 414-422, 2015.

[56] J. S. Wooten, T. N. Nick, A. Seija, K. E. Poole, and K. B. Stout, "High-fructose intake impairs the hepatic hypolipidemic effects of a high-fat fish-oil diet in C57BL/6 mice," Journal of Clinical and Experimental Hepatology, vol. 6, no. 4, pp. 265-274, 2016.

[57] X. Li, Z. Xu, S. Wang et al., "Emodin ameliorates hepatic steatosis through endoplasmic reticulum-stress sterol regulatory element-binding protein 1c pathway in liquid fructosefeeding rats," Hepatology Research, vol. 46, no. 3, pp. E105-E117, 2016.

[58] N. Wu, L. K. Sarna, S.-Y. Hwang et al., "Activation of 3hydroxy-3-methylglutaryl coenzyme A (HMG-CoA) reductase during high fat diet feeding," Biochimica et Biophysica Acta (BBA)Molecular Basis of Disease, vol. 1832, no. 10, pp. 1560-1568, 2013.

[59] G. Ji, X. Zhao, L. Leng, P. Liu, and Z. Jiang, "Comparison of dietary control and atorvastatin on high fat diet induced hepatic steatosis and hyperlipidemia in rats," Lipids in Health and Disease, vol. 1023 pages, 2011.

[60] J. H. Stern, J. M. Rutkowski, and P. E. Scherer, "Adiponectin, leptin, and fatty acids in the maintenance of metabolic homeostasis through adipose tissue crosstalk," Cell Metabolism, vol. 23, no. 5, pp. 770-784, 2016.

[61] S. Lasker, M. M. Rahman, F. Parvez et al., "High-fat dietinduced metabolic syndrome and oxidative stress in obese rats are ameliorated by yogurt supplementation," Scientific Reports, vol. 9, no. 1, pp. 1-15, 2019.

[62] F. Savari, S. A. Mard, M. Badavi, A. Rezaie, and M. K. GharibNaseri, "A new method to induce nonalcoholic steatohepatitis (NASH) in mice," BMC Gastroenterology, vol. 19, no. 1, 2019.

[63] S. Furukawa, M. Matsuda, S. Furukawa, T. Fujita, M. Shimabukuro, and M. Iwaki, "Increased oxidative stress in obesity and its impact on metabolic syndrome," Journal of Clinical Investigation, vol. 114, no. 12, pp. 1752-1761, 2017.

[64] F. V. Francisqueti, L. C. T. Chiaverini, L. C. T. Chiaverini et al., "The role of oxidative stress on the pathophysiology of metabolic syndrome," Revista da Associação Médica Brasileira, vol. 63, no. 1, pp. 85-91, 2017.

[65] E. Hopps, D. Noto, G. Caimi, and M. R. Averna, "A novel component of the metabolic syndrome: the oxidative stress," Nutrition, Metabolism and Cardiovascular Diseases, vol. 20, no. 1, pp. 72-77, 2010.

[66] L. N. Maslov, N. V. Naryzhnaya, A. A. Boshchenko, S. V. Popov, V. V. Ivanov, and P. R. Oeltgen, "Is oxidative stress of adipocytes a cause or a consequence of the metabolic syndrome?" Journal of Clinical \& Translational Endocrinology, vol. 15, pp. 1-5, 2019.

[67] A. Ayala, M. F. Muñoz, and S. Argüelles, "Lipid peroxidation: production, metabolism, and signaling mechanisms of malondialdehyde and 4-hydroxy-2-nonenal," Oxidative Medicine and Cellular Longevity, vol. 2014, Article ID 360438, 31 pages, 2014.

[68] N. Allocati, M. Masulli, C. Di Ilio, and L. Federici, "Glutathione transferases: substrates, inihibitors and pro-drugs in cancer and neurodegenerative diseases," Oncogenesis, vol. 7, no. 1, 2018.

[69] G. R. Buettner, "Superoxide dismutase in redox biology: the roles of superoxide and hydrogen peroxide," Anti-Cancer Agents in Medicinal Chemistry, vol. 11, no. 4, pp. 341-346, 2011.

[70] A. Falodun, V. Imieje, O. Erharuyi et al., "Evaluation of three medicinal plant extracts against Plasmodium Falciparum and selected microganisms," African Journal of Traditional, Complementary and Alternative Medicines, vol. 11, no. 4, pp. 142-146, 2014. 